\section{Experiências de convergência entre ensino, pesquisa e extensão na formação inicial de futuros pedagogos}

\author{
Cristiane Aparecida Medeiros \\ Montanini \\ cristianeamm@gmail.com
}

Adriana Moreira da Rocha Veiga

adrianaufsm@gmail.com
Professoras e pesquisadoras da Universidade Federal de Santa Maria, Brasil.
Integración de la docencia y la extensión /

Intervenciones

RECEPCIÓN: 21/06/16

ACEPTACIÓN FINAL: 31/08/16

\section{Resumo}

O presente artigo apresenta os resultados do Trabalho de Conclusão do Curso de Pedagogia, a partir de pesquisa desenvolvida e orientada pelas autoras, realizada na Universidade Federal de Santa Maria, no ano de 2014. O objetivo geral foi analisar as experiências vivenciadas na relação entre o ensino, pesquisa e extensão pelos acadêmicos do curso de Pedagogia Licenciatura Plena da própria universidade. A revisão teórica do trabalho abordou os significados do ensino, da pesquisa e da extensão para a formação universitária e as possibilidades de estudos oferecidos no percurso da graduação. Utilizando uma abordagem qualitativa, por meio de questões abertas propostas aos estudantes, a pesquisa colheu relatos das experiências individuais vivenciadas durante o percurso acadêmico. As contribuições dos sujeitos da pesquisa foram analisadas mediante a Análise Textual Discursiva (ATD) proposta por Roque Moraes (2007). Os resultados corroboram com a importância do tripé ensino-pesquisa-extensão na formação e na docência universitária.

\section{Palavras-chave}

- Tripé ensino-pesquisa-extensão

- Formação do pedagogo

- Iniciação científica

\section{Resumen}

Este artículo presenta los resultados del Trabajo de Conclusión de la carrera de Pedagogía desarrollado/dirigido por los autores en la Universidade Federal de Santa Maria en el año 2014. El objetivo general fue analizar las experiencias y la relación entre la docencia, la investigación y la extensión académica en el curso de Pedagogía. El marco teórico del trabajo aborda los significados de la enseñanza, la investigación y la extensión para la formación universitaria y las posibilidades de estudio que se ofrecen en el curso de graduación (transcurso/trayecto de la carrera). Utilizando un enfoque cualitativo, a través de preguntas abiertas propuestas a los estudiantes, la investigación reunió relatos de experiencias individuales vividas durante el trayecto académico. Las contribuciones de los participantes en la investigación fueron examinadas por análisis textual discursivo (ATD), propuesto por Roque Moraes (2007). Los resultados corroboran la importancia de la tríada enseñanza-investigaciónextensión en la formación y en la enseñanza universitaria.

\section{Palabras-clave}

- Integración entre enseñanza-investigación-extensión

- Formación del pedagogo

- Iniciación científica este artículo

Medeiros Montanini, C. A. y Moreira da Rocha Veiga, A.

(2016). Experiências de convergência entre ensino, pesquisa

e extensão na formação inicial de futuros pedagogos.

En Revista +E versión digital, (6), pp. 320-329. Santa Fe,

Argentina: Ediciones UNL. 


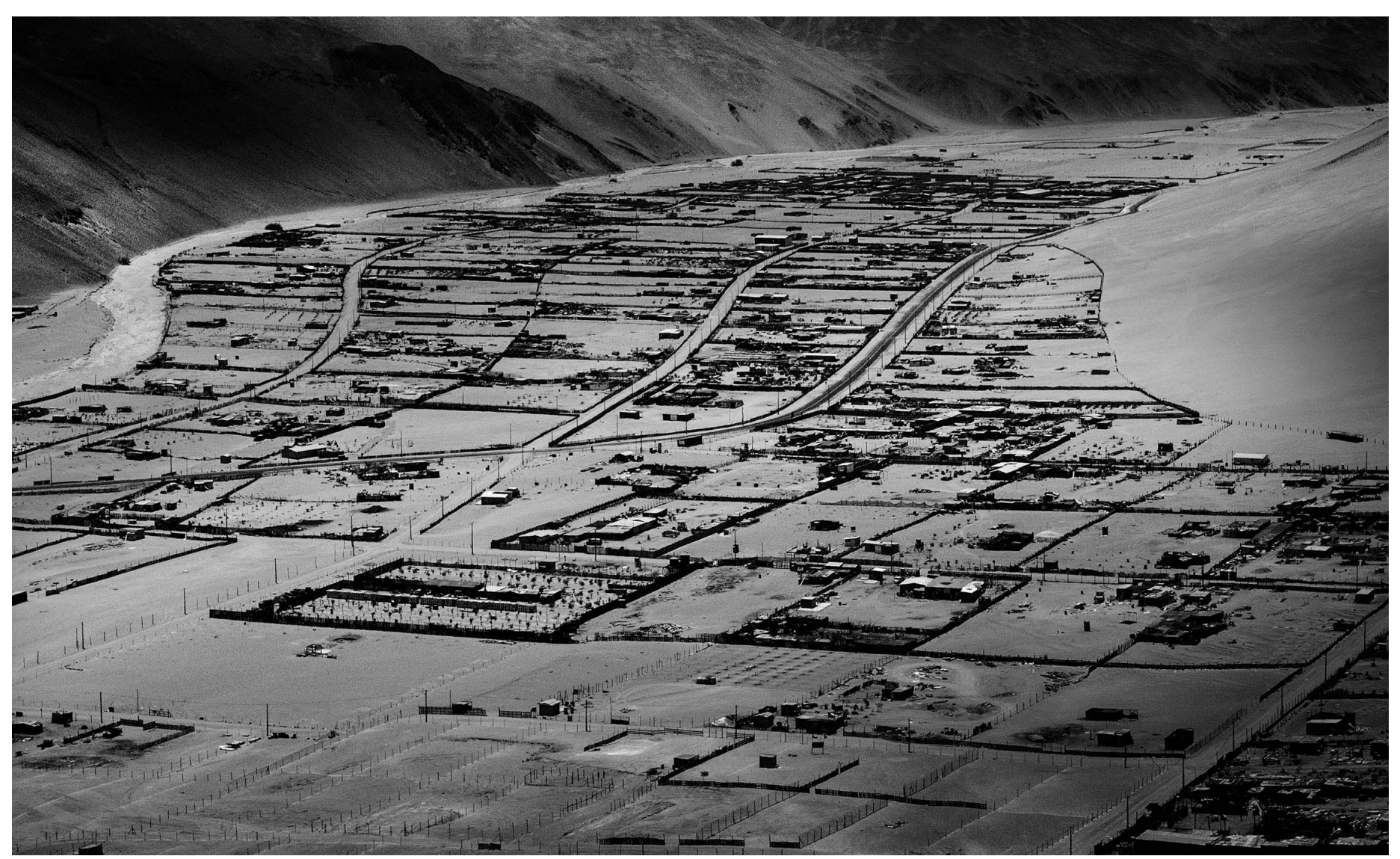

(C) Oscar Dechiara

\section{Introdução}

Este artigo apresenta resultados de um Trabalho de Conclusão de Curso (TCC) realizado na Universidade Federal de Santa Maria no ano de 2014, a partir de pesquisa qualitativa, utilizando questionário aberto preenchido via online, cuja divulgação é permitida via Termo de Consentimento individual dos participantes, todos estudantes participantes de Projetos de ensino, pesquisa ou extensão como bolsistas de iniciação científica, portanto ligados a programas de fomento.

A relação das autoras com a pesquisa é de pesquisadora e orientadora. Uma vez que o tema está fortemente ligado às vivências acadêmicas da primeira autora, decidiu-se manter a narrativa na primeira pessoa do singular, refletindo o processo reflexivo durante a sua formação e que culmina neste trabalho conclusivo. Com a mesma intenção, optou-se pela sistematização do texto original em um corpus, integrando matriz teórica, resultados e discussão.

$\mathrm{O}$ artigo traz os resultados de uma pesquisa acadêmica, cujo processo reflexivo envolve a autora, como bolsista de iniciação científica e de programa de extensão desde o início do curso e a sua orientadora, como participante desse processo. $\mathrm{O}$ aprendizado é mútuo, pois a docência, tanto quanto a discência, alicerçadas na experiência de ensino, pesquisa e extensão, como um tripé do processo formativo, trazem experiências singulares que de outra forma não permitiriam a vivência prática do que se projeta teoricamente. O convite à leitura e ao compartilhamento de saberes está posto ao leitor.

\section{Apontamentos iniciais}

A escolha pelo tema de estudo foi a partir das minhas experiências como graduanda do Curso de Pedagogia Licenciatura Plena da Universidade Federal de Santa Maria e que simultaneamente desenvolvi atividades de pesquisa e extensão junto ao grupo de pesquisa da Universidade Federal de Santa Maria. O trabalho sob a orientação da professora da Universidade Federal de Santa Maria, também líder do grupo de pesquisa acima citado, teve como título "Convergências entre teoria e prática na formação inicial do pedagogo: articulando ensino, pesquisa e extensão". A revisão teórica do trabalho abordou os significados do ensino, da pesquisa e da extensão no Brasil para a formação universitária e as possibilidades de estudos oferecidos no percurso da graduação. Nesta pesquisa qualitativa que procurou compreender 
os fenômenos segundo a perspectiva dos sujeitos (Godoy, 1995), sua busca foi a partir dos relatos das experiências individuais de discentes por meio de um questionário com tópicos guia pertinentes ao tema. $E$ as contribuições dos sujeitos da pesquisa foram analisadas a partir das concepções da Análise Textual Discursiva (Moraes, 2007).

Neste percurso reconheci que os aprendizados vivenciados serviram como um apoio e ampliação de conhecimentos ao curso que escolhi para a minha formação inicial. Compreendendo que escutar o outro é uma forma de aprender, pois a partir das vozes de outras pessoas, podemos ressignificar e ampliar o entendimento de temas voltados à Educação que aprimora tanto a vida pessoal, quanto a profissional.

O aprender está presente em vários espaços, podendo ser de forma institucional ou não, emergindo na troca com os colegas e com os professores do meio escolar e do ensino superior, nos projetos de pesquisa e atividades de extensão, em situações do cotidiano e nas trocas de experiências da vida diária. Em todo momento a educação se dá em qualquer espaço, conforme consta na Lei de Diretrizes e Bases n. 9.394/1996:

"Art. $1^{\circ}$ - A educação abrange os processos formativos que se desenvolvem na vida familiar, na convivência humana, no trabalho, nas instituições de ensino e pesquisa, nos movimentos sociais e organizações da sociedade civil e nas manifestações culturais"(Ministério da Educação de Brasil, 1996).

O ser humano se constitui nas experiências cotidianas e no convívio com outros que de alguma forma se fazem presentes na vida em sociedade. Nos seus primeiros passos para conhecer o mundo tem a família e aos poucos outros espaços, outros indivíduos e suas individualidades começam a fazer parte do seu desenvolvimento. Em certo momento este terá acesso e vínculo institucional, no caso, começamos com o escolar para construir conhecimentos mais específicos de acordo com a fase de vida, para conhecer um pouco mais do mundo que o cerca e futuramente a universidade que delimitará um pouco mais de acordo com o conhecimento específico escolhido para futura atuação profissional.

No caso dessa pesquisa o aprender percorreu na formação inicial institucional universitária, a partir da questão:"Quais as possíveis contribuições da vivência acadêmica, articulada entre o ensino, a pesquisa e a extensão na formação do pedagogo na Universidade Federal de Santa Maria?", determinando o objetivo geral, ou seja, analisar as possíveis contribuições na relação entre o ensino, pesquisa e extensão percebidas pelos acadêmicos do curso de Pedagogia Licenciatura Plena da Universidade Federal de Santa Maria durante a sua formação inicial. E os objetivos específicos se constituíram em:

1) Identificar experiências vivenciadas pelos acadêmicos, referentes à pesquisa e extensão concomitante ao ensino durante o curso de Pedagogia;

2) Perscrutar se houve contribuições efetivas no percurso acadêmico;

3) Descrever os elementos presentes nos relatos dos discentes que evidenciam as contribuições das vivências acadêmicas articuladas entre o ensino, a pesquisa e a extensão.

Institucionalmente, o processo formativo do Curso de Pedagogia tem como objetivo formar professores em nível superior para a docência na Educação Infantil e Anos Iniciais do Ensino Fundamental (até o $5^{\circ}$ ano), com capacitação para atuar em diferentes modalidades de ensino e outras áreas que há necessidades dos conhecimentos pedagógicos. No percurso desta formação, tendo como o seu objeto de estudo a prática educativa, é importante que a dimensão teórica e prática caminhem juntas para construção dos conhecimentos.

\section{Percorrendo caminhos formativos na docência articulada - ensino, pesquisa e extensão}

O Curso de Pedagogia na Universidade Federal de Santa Maria teve seus primeiros movimentos em 1955, seguindo todas as determinações legais para seu funcionamento que foram se transformando no decorrer do tempo. Seu escopo é oferecer aos futuros pedagogos possibilidades para construir seus primeiros conhecimentos para uma ação docente com qualidade conciliando teoria e prática. Atualmente a instituição oferece o curso na modalidade presencial nos períodos diurno e noturno, assim como a distância.

Na minha percepção o curso ofereceu uma visão mais teórica sobre a minha atuação docente, a prática teve breves momentos no decorrer do curso e o mesmo foi perceptível nos relatos de alguns colegas de turma. A importância da prática, conforme Pimenta: "a prática dá origem a novas ideias, que farão o homem ver, conhecer o mundo de maneira mais extensa, aprofundada e exata" (1994:96).

As finalidades existentes a cada momento determinam a prática, que, por sua vez, determinam o surgimento de novas finalidades. 
A prática na escola é necessária na formação inicial do pedagogo, pois, perceber, investigar e refletir na práxis é uma das formas que realmente se aprende para compartilhar com o outro. Além da vivência escolar a prática pode estar presente dentro da própria sala de aula universitária ou em outros espaços da instituição ou fora dela, como por exemplo, participando dos projetos de pesquisa e/ ou dos programas de extensão oferecidos pela instituição. Conhecer a teoria e a prática no ensino, em projetos de pesquisa e programas de extensão amplia a visão do real, o acadêmico estará mais próximo dos estudos e ações abordadas na atualidade que darão origem a novas ideias e finalidades para a educação.

Para ampliação dos seus conhecimentos os acadêmicos têm a possibilidade de se integrarem nos projetos de pesquisas desenvolvidos pela universidade, que envolvem estudos de variadas especificidades. Neste caso, sobre a Educação. A prática da pesquisa, segundo Severino:

"A pesquisa, como processo de construção do conhecimento, tem uma tríplice dimensão: uma dimensão propriamente epistêmica, uma vez que se trata de uma forma de conhecer o real; uma dimensão pedagógica, pois é por intermédio de sua prática que ensinamos e aprendemos significativamente; uma dimensão social, na medida em que são seus resultados que viabilizam uma intervenção eficaz na sociedade através da atividade de extensão". (2009:26)

A pesquisa abrange várias áreas do conhecimento em uma sequência contínua entre inquirir e construir uma nova compreensão do mundo que nos cerca. No campo da Educação a pesquisa envolve investigação entre os campos das ciências humanas e sociais, para acompanhar a evolução de uma sociedade idealizando uma melhor qualidade em seus vários âmbitos educacionais.

Segundo Freire, "não há ensino sem pesquisa e pesquisa sem ensino" (1996:29), esta prática não precisa ser incentivada somente no meio acadêmico, mas coexistir durante todo o percurso no processo de ensino e aprendizagem de um educando sob a orientação de seu professor. Freire define:

"No meu entender o que há de pesquisador no professor não é uma qualidade ou uma forma de ser ou de atuar que se acrescente à de ensinar. Faz parte da natureza da prática docente a indagação, a busca, a pesquisa. O que se precisa é que, em sua formação permanente, o professor se perceba e se assuma, porque professor, como pesquisador". (1986:29)
Como continuidade do ensino e a pesquisa, contamos com a extensão que, segundo Severino, há necessidade de um envolvimento universitário com esta prática:

"A extensão tem grande alcance pedagógico, levando o jovem estudante a vivenciar sua realidade social. É por meio dela que o sujeito/aprendiz irá formando sua nova consciência social. A extensão cria então um espaço de formação pedagógica, numa dimensão própria e insubstituível”. (2007:32)

Neste percurso de estudos em projetos de pesquisa os integrantes procuram identificar os problemas para futuros debates, análises dos dados e reflexões de quais as soluções necessárias para atender o cotidiano das comunidades referente ao ensino $e$ aprendizagem que podem ser de âmbito local, regional ou nacional. A pesquisa em extensão é uma ação junto a uma comunidade direcionando as práticas acadêmicas para as questões sociais, políticas, econômicas e ambientais da sociedade. Segundo o Fórum de Pró-Reitores de Extensão das Universidades Públicas Brasileiras (FORPROEX), com constituição em 1987: "Extensão Universitária é o processo educativo, cultural e científico que articula o Ensino e a Pesquisa de forma indissociável e viabiliza a relação transformadora entre Universidade e Sociedade" (Política de Extensão da Universidade Federal de Santa Maria, 2008:2). Com base na Lei $n^{\circ}$ 9.394- Diretrizes e Bases da Educação Nacional, de 20 de Dezembro de 1996 - em seu capítulo IV com foco na Educação Superior, conforme Art. 43 que vincula educação superior e a extensão universitária com a seguinte finalidade:

"IV - promover a divulgação de conhecimentos culturais, científicos e técnicos que constituem patrimônio da humanidade e comunicar o saber através do ensino, de publicações ou de outras formas de comunicação;

(...)

$\mathrm{VI}$ - estimular o conhecimento dos problemas do mundo presente, em particular os nacionais e regionais, prestar serviços especializados à comunidade e estabelecer com esta uma relação de reciprocidade;

VII - promover a extensão, aberta à participação da população, visando à difusão das conquistas e benefícios resultantes da criação cultural e da pesquisa científica e tecnológica geradas na instituição".

A extensão não pode ser compreendida como ação promovida por professores e alunos como uma mera assistência social ao 
outro sem escutar o que a sua realidade e experiência comunica, mas como uma continuidade da construção do conhecimento, no amálgama com o ensino e a pesquisa entre diferentes indivíduos com suas formas de pensar e agir na construção de um mundo e de si mesmo nesta interação. Paulo Freire não aceitava a nomenclatura "extensão" devido às interpretações da palavra, entre algumas delas citadas em sua obra Comunicação ou Extensão?, destaco: estender algo a alguém; transmissão de um superior para alguém inferior; aqueles que levam e outros recebem passivamente. O autor substitui a "extensão" pelo conceito da "comunicação", trazendo a compreensão do verdadeiro significado desta prática como troca de saberes em que nenhum sujeito é passivo, mas com o pensamento de:

"Conhecer, na dimensão humana, que aqui nos interessa, qualquer que seja o nível em que se dê, não é o ato através do qual um sujeito, transformado em objeto, recebe, dócil e passivamente, os conteúdos que outro lhe dá ou impõe. (...) O conhecimento, pelo contrário, exige uma presença curiosa do sujeito em face do mundo. Requer sua ação trans-formadora sobre a realidade. Demanda uma busca constante, implica em invenção e em reinvenção". (1980:16)

Para atender os objetivos do ensino de forma concomitante à pesquisa e as atividades de extensão apresentados acima, os acadêmicos têm a possibilidade de unir-se aos estudos dos grupos de pesquisa existentes no Centro de Educação daUniversidade Federal de Santa Maria para esta articulação. Os acadêmicos do curso de Pedagogia ou de outras áreas específicas do conhecimento que têm o interesse de explorar um pouco mais as relações entre teoria e prática dos temas que envolvam a Educação têm a possibilidade de participar dos Grupos de Pesquisa disponíveis no Centro de Educação. Cada qual com sua linha de pesquisa proporcionam estudos consideráveis para a formação inicial, na época foi localizado no centro um total de vinte e cinco grupos com suas especificidades de estudos.

Um dos requisitos legais, a Constituição Federal de 1988 em seu Art. 207, especifica que "as universidades gozam de autonomia didático-científica, administrativa e de gestão financeira e patrimonial, e obedecerão ao princípio da indissociabilidade entre ensino, pesquisa e extensão".

Ao longo do tempo alguns estudos apontam a importância das instituições de ensino superarem a distância entre ensino, pesquisa e extensão, por serem três eixos com suas particularidades que precisam estar articulados entre si por serem atividades construtivas no ensino superior. Apresento algumas informações sobre o que vem se delineando sobre esta indissociabilidade que precisa da devida atenção na atualidade tanto na graduação e pósgraduação. Para entender estes três eixos de forma específica e como se interligam, Frantz e Silva apresenta a seguinte explicação:

“a) o ensino: articular as ciências existentes, conhecer seus produtos e formar profissionais. Legitima-se no espaço social pela quantidade e qualidade dos diplomas concedidos;

b) a pesquisa: construir novos, confirmar ou contestar conhecimentos existentes. Legitima-se junto à sociedade pela produção de tecnologias úteis a ela e pela orientação científica na resolução dos seus problemas;

c) a extensão: articular os interesses do ensino e da pesquisa com os interesses sociais. Legitima-se pela presença de agentes universitários nos setores sociais, executando ações de serviços, assistências, projetos culturais, ensino de extensão etc.". (2002:217)

Ao final do curso de Pedagogia percebi que no percurso de preparação para o contexto da sala de aula o pedagogo não pode somente pensar em reproduzir, ou seja, "testar as teorias" apresentadas durante o curso de graduação, mas precisa refletir sobre os saberes construídos e como vai conduzir a sua prática educativa. O refletir está em observar o real e relacionar às teorias, ou vice-versa, estudar as teorias e percebê-las como estão presentes e se movimentam no cotidiano. Este caminho será por meio de procedimentos de investigação como: o registrar, buscar e organizar informações, analisar e comparar os dados, para fazer um levantamento do que fora percebido na busca de como melhorar a sua ação para contribuir e comunicar suas experiências à sociedade. Nesta compreensão percebo que o professor é um eterno pesquisador, pois, precisará sempre pensar em sua prática, precisando estar inteirado das mudanças na área da Educação no decorrer dos tempos e escutar todos os sujeitos que dividem este mesmo espaço do ensinar e aprender sobre suas experiências para estar em contínua formação pessoal e profissional. Ao participar dos grupos de pesquisa o acadêmico amplia a compreensão desta relação entre ensino, pesquisa e extensão. Com o foco na linha de pesquisa do grupo que está inserido, investiga temas para se apropriar de novos conhecimentos para serem compartilhados e transformados. E nesta contínua relação de ensino e aprendizagem coexistem sujeitos dentro e fora dos muros universitários com diferentes experiências e saberes. Para aprender com o outro, foi elaborado uma matriz guia para a investigação junto aos sujeitos da pesquisa, a partir do tópico e sua descrição, contemplado dezesseis questões específicas para responder os subitens. Apresentado na tabela abaixo, o tópico e suas descrições do que procurou identificar. 
Após a identificação dos alunos junto aos departamentos responsáveis do Centro de Educação que podiam contribuir com a pesquisa, foi enviado questionário para o e-mail de cada um deles para compreender nos seus relatos quais contribuições a partir da tríade ensino, pesquisa e extensão.

O tópico a escolha pela experiência questionou via formulário, "O que fez você optar em participar de Projetos de Pesquisa e/ou Programas de Extensão, durante o percurso do curso de graduação?", as respostas esboçaram três aspectos: [a] preocupação com a formação; [b] construção do conhecimento e [c] continuidade da formação universitária.

O primeiro item [a] preocupação com a formação, os relatos se delinearam sobre a importância de aprofundamento teórico, além do apresentado em sala de aula, assim como, oportunidade de vivências e experiências para a formação inicial que a instituição de ensino oferece, entendendo a prática como a busca de uma formação permanente já em seus primeiros passos acadêmicos, como percebido nos relatos abaixo:

- Resposta sujeito A1: A busca por um maior e mais aprofundado referencial teórico acerca das temáticas pesquisadas. A oportunidade de experienciar novas vivências e experiências e oportunidades de formação complementar à minha formação, à formação ofertada pelo curso. Aproveitar as oportunidades e possibilidades formativas da universidade.

- Resposta sujeito A2: No terceiro semestre do curso percebi que é necessário ir além do que é oferecido no contexto das salas de aula, precisamos ser sujeitos de nossa formação, ir em busca de uma formação permanente sempre. Essa busca pela autonomia dentro de minha formação me fez procurar por projetos e grupos.

Tabela 1. Matriz guia com os tópicos de investigação.

\begin{tabular}{|c|c|}
\hline Tópico & Descrição \\
\hline Identificação & $\begin{array}{l}\text { Pesquisar sobre o perfil de cada acadêmico do curso } \\
\text { de Pedagogia que participou desta convergência entre } \\
\text { ensino, pesquisa e/ou extensão. }\end{array}$ \\
\hline A escolha pela experiência & $\begin{array}{l}\text { Pesquisar na fala dos acadêmicos o porquê da escolha } \\
\text { de inserir-se em projetos de pesquisa e/ou extensão. }\end{array}$ \\
\hline As experiências & $\begin{array}{l}\text { Pesquisar o que o acadêmico aprendeu; quais os } \\
\text { seus desafios; as relações junto ao grupo de pesquisa } \\
\text { e/ou extensão. }\end{array}$ \\
\hline As convergências & $\begin{array}{l}\text { Pesquisar o que o acadêmico percebe de contribuição } \\
\text { na sua formação inicial na práxis em participar } \\
\text { nos grupos de estudos em projetos pesquisa e/ou } \\
\text { atividades de extensão }\end{array}$ \\
\hline
\end{tabular}

Objetivando [b] construção do conhecimento, os relatos em conhecer o novo e agregar ao que já conhece na interação com outros que fazem parte do grupo de pesquisa. Intensificar a prática da pesquisa reconhecendo como uma forma de construção e aperfeiçoamento profissional, como mostram os relatos:

- Resposta sujeito A4: Tinha por objetivo buscar ampliar as possibilidades de construção de conhecimento e aperfeiçoamento de minha prática profissional com o intuito de seguir minha formação acadêmica com a possibilidade de ingressar no programa de pós-graduação.

- Resposta sujeito A5: Procurei me inserir logo no início do curso em grupos de pesquisa e trabalhar num projeto, visando agregar conhecimento aos que já possuo, fora a importância de estar fazendo pesquisa. Atualmente estou num grupo de pesquisa onde sou bolsista, onde não tenho nenhum tipo de conhecimento na área do projeto, está sendo muito importante pelas trocas de conhecimento, onde o grupo é bem variado, ou seja, profissionais de várias áreas, não somente da educação. Para o currículo cada acréscimo que você fizer é ponto positivo na sua carreira profissional.

Pensando no futuro [c] continuidade da formação universitária -após a graduação o acadêmico tem o interesse de continuar seus estudos e compreende que ao estar vinculado a um grupo de pesquisa que desenvolvem as atividades de pesquisa e de extensão, haverá mais possibilidade de ingresso aos programas de pós-graduação ao conciliar em seu currículo os três pilares ensino, pesquisa e extensão. Como apresentam os relatos: - Resposta sujeito A4: Com o intuito de seguir minha formação acadêmica com a possibilidade de ingressar no programa de pósgraduação.

- Resposta sujeito A5: Para o currículo cada acréscimo que você fizer é ponto positivo na sua carreira profissional.

- Resposta sujeito A6: Possibilidade de continuar a vida acadêmica.

Sobre a escolha de participação em projetos de pesquisa e/ou extensão, os três aspectos relatados demonstram que os acadêmicos traçam o percurso de formação inicial coexistindo a preocupação e interesse de uma formação contínua já em seus primeiros passos. Aos poucos querem delinear a construção de conhecimentos além do que a sala de aula universitária proporciona, com almejo de seguimento da sua constituição profissional.

Sobre as experiências, as questões tinham como propósito identificar no relato dos acadêmicos quais foram seus aprendizados, desafios e as relações interpessoais junto ao grupo de pesquisa e/ou extensão. 


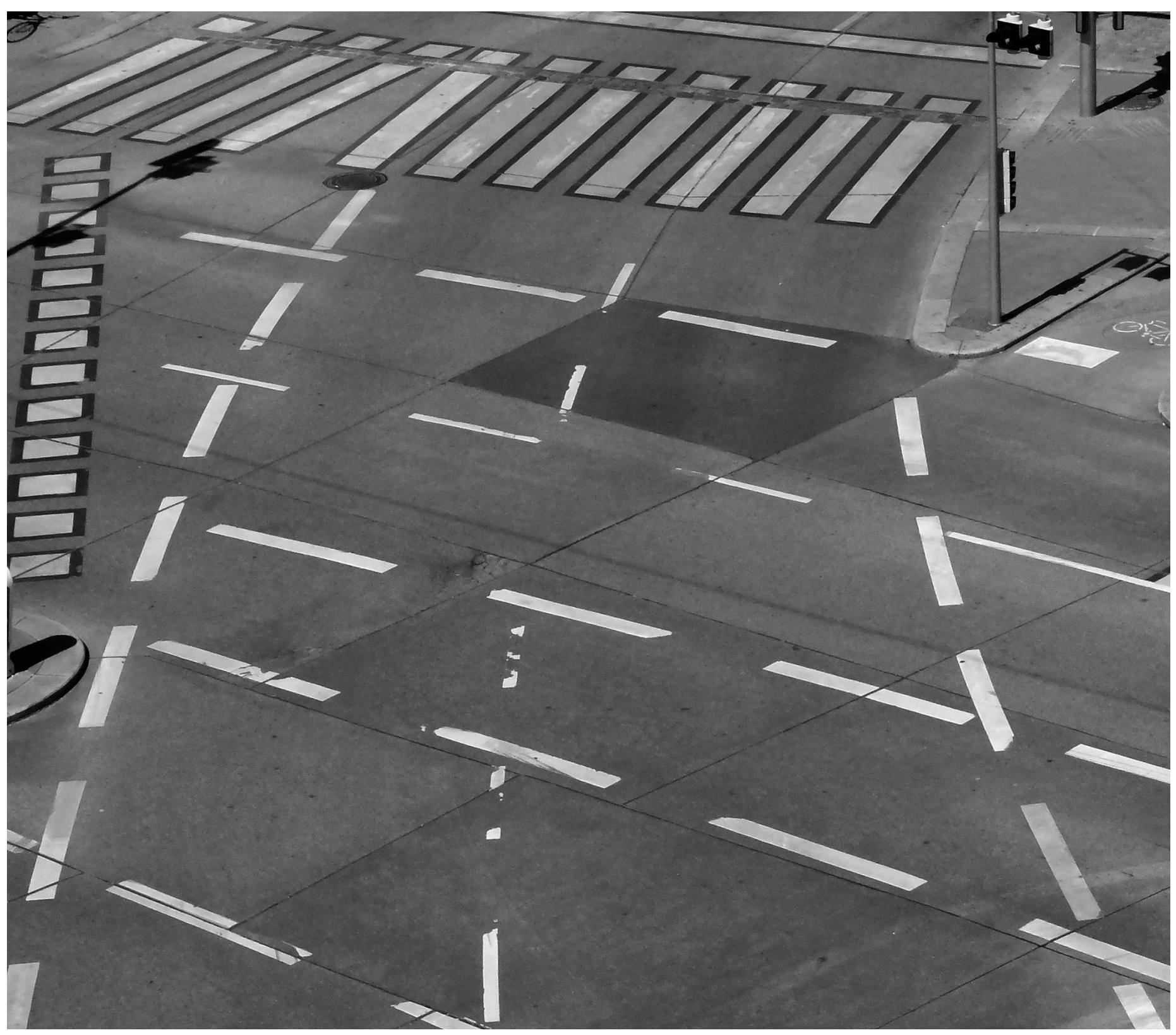

(c) Oscar Dechiara

\section{6}

a extensão não pode ser compreendida como ação promovida por professores e alunos como uma mera assistência social ao outro sem escutar o que a sua realidade e experiência comunica 
Foram desenvolvidas quatro perguntas para maior clareza destas peculiaridades: [1] Como foi a sua experiência participando dos Projetos de Pesquisa junto a um grupo de estudos? [2] Como foi sua experiência participando dos Programas de Extensão junto a um grupo de estudos? [3] Quais os desafios encontrados neste percurso: como participante em Grupo de Pesquisa e/ ou Programas de Extensão? [4] Como foi sua relação com os integrantes dos projetos e programas, sejam eles: professores, colegas bolsistas, acadêmicos de graduação, de mestrado ou de doutorado?

Na primeira questão os relatos apontaram os seguintes elementos quanto às experiências em projetos de pesquisa junto a um grupo de estudos: [a] aprende a ter um olhar crítico sobre sua formação; [b] aprende as dimensões da formação; [c] aprende sobre o desenvolvimento e crescimento coletivo na formação; [d] aprende a compreender e sistematizar os conteúdos trabalhados no decorrer do curso; [e] aprende uma construção do conhecimento com integrantes de diferentes áreas do conhecimento e níveis de formação universitária; [f] aprende determinadas atividades de rotina e específicas como integrante.

A segunda questão apresentou alguns acadêmicos que não participaram de atividades de extensão e os outros que manifestaram vivências prazerosas e construtivas, em que a prática da extensão proporciona vivenciar uma determinada realidade para conhecer um espaço e os sujeitos que a ele pertence para uma interação do social e do institucional com o intuito de uma ação transformadora reflexiva para a construção de novos conhecimentos na articulação da teoria e a da prática. Os relatos apontaram: [a] articulação da teoria e da prática no contexto escolar; [b] contribuição na formação pedagógica; [c] aproximação de realidades. Como exposto nos relatos abaixo:

- Resposta sujeito A1: Muito interessante por possibilitar vivenciar na prática o contexto da escola, articulando teoria e prática.

- Resposta sujeito A2: No ano de 2013 iniciei minha participação na Hora do Conto, também como voluntária; tal programa foi tão intenso que no presente ano atuo como bolsista do mesmo.
O primeiro projeto foi de grande importância sim, porém não foi muito além do que o projeto de pesquisa já me proporcionava; no que diz respeito ao Hora do Conto, esse projeto fez com que eu me redescobrisse aos pouquinhos, me levou à classe hospitalar, minha grande paixão hoje, me presenteou com gargalhadas, olhos arregalados e a espontaneidade de pequenos acamados do Centro de Tratamento a Crianças e Adolescentes com Câncer do HUSM, com a emoção de pais e mães dessas crianças e adolescentes; me presenteou com a criatividade e a imaginação de crianças da Educação Infantil. Poder vivenciar momentos como os que o programa me proporciona é maravilhoso, esses momentos contribuem para minha formação inicial me incentivando a querer buscar sempre mais, estudar, ler, pesquisar e principalmente estar lá com aquelas crianças que já são especiais. Além disso, o programa funciona como uma iniciação à docência, me proporcionando a prática orientada antes do estágio supervisionado, o que me deixa mais tranquila para tal, acreditando que estou pronta para a inserção na sala de aula.

- Resposta sujeito A3: A possibilidade de aproximação das escolas da rede pública. Acredito ser importante a aproximação das redes privadas, o que hoje não acontece com frequência. Este também é um contexto de trabalho que precisa ser discutido e aproximado.

A terceira questão ao perscrutar sobre as experiências dos desafios encontrados, os relatos indicaram dimensões antes da inserção ao grupo de pesquisa e outros que vem enfrentando no percurso já como integrante. Conforme relatos que seguem:

[a] dificuldade para escolher o grupo de pesquisa:

- Resposta sujeito A1: Escolher o grupo de pesquisa que desse suporte às minhas demandas de formação e que viesse de encontro às minhas inquietações e às questões que me mobilizaram para a pesquisa.

[b] importância de construir vínculos significativos e relações de respeito quando uma pesquisa ultrapassa o espaço universitário. - Resposta sujeito A2: O desafio encontrado diz respeito à rejeição das instituições de ensino em participar dos projetos e programas, 
pois relatam que acadêmicos e professores universitários "usam" a escola e não levam um retorno, não fazem um diálogo final, apresentando os resultados da pesquisa. Sempre foi uma preocupação e responsabilidade do grupo em fazer esse diálogo final, deixando inclusive cópias de relatórios nessas instituições; acredito que os coordenadores de projetos das universidades deveriam atentar para essa pequena falha.

[c] suposta percepção de distanciamento na articulação dos três eixos ensino, pesquisa e extensão.

- Resposta sujeito A4: O principal desafio é conseguir articular os conceitos e conhecimentos discutidos no curso com o que está sendo discutido no grupo.

[d] a falta do tempo.

- Resposta sujeito A3: O grande desafio de hoje é o tempo. Acabamos por nos dedicarmos demais à vida acadêmica e nos distanciamos de outras atividades tão importantes quanto teatro, cinema e até mesmo as atividades familiares.

[e] dificuldades para as leituras, relações entre os integrantes do grupo e elaboração de artigos.

- Resposta sujeito A5: No projeto de pesquisa estão sendo as novas leituras que estão me pedindo mais atenção e pesquisa, por serem de um nível maior ao qual estou habituada. Mas é um desafio positivo, por agregar conhecimento.

No de extensão o maior desafio era a desunião e a competitividade no sentido negativo, não havia uma organização de funcionamento do grupo, deixar para fazer as atividades em cima dos prazos, sendo que havia tempo para executar.

- Resposta sujeito A6: A maior dificuldade que encontrei foi escrever artigos devido à falta de conhecimento sobre o mesmo.

Ao indagar sobre as relações com os integrantes dos projetos e programas a questão de número quatro evidenciou resultados de uma relação interpessoal positiva com os integrantes do grupo.

Em alguns momentos aparecem críticas, mas simultaneamente há compreensão de respeito às diferentes individualidades, conforme a podemos observar a seguir:

- Resposta sujeito A1: Muito boa. De parceria, compartilhamento de conhecimentos e aprendizagens.

- Resposta sujeito A2: A relação com os demais integrantes sempre foi boa.

- Resposta sujeito A3: Uma relação de respeito e solidariedade. Às vezes nos indignamos por querermos o mesmo comprometimento e responsabilidade de todos os integrantes, mas no final acabamos tendo que entender e respeitar os limites e o tempo do outro. Isso também é uma aprendizagem, que não é tão fácil de ser desenvolvida!

- Resposta sujeito A4: Foi muito boa. Pois sempre houve a possibilidade de aprender e crescer juntos, desenvolvendo um trabalho colaborativo.
- Resposta sujeito A5: A minha relação é boa, como tenho perfil mediadora e não retenho o conhecimento somente comigo, procuro sempre trabalhar para que o grupo tenha todas as informações possíveis.

- Resposta sujeito A6: Somos um grupo bem unido podemos contar com a colaboração de todos inclusive de ex-integrantes do grupo.

O incentivo de boas relações interpessoais é essencial para o processo da formação inicial, o acadêmico precisa saber como harmonizar as relações intrapessoais e interpessoais para conseguir equilibrar os seus desejos, anseios e emoções e ao mesmo tempo respeitar os outros que pertencem ao mesmo espaço social. Este ao presenciar e pertencer às diferentes experiências de convívio, sejam eles favoráveis ou desfavoráveis, futuramente encontrará os melhores caminhos para estabelecer uma agradável relação profissional de aprendizagem com os alunos e com todos os outros que pertencem ao espaço escolar que atuará.

Com os relatos apresentados pelos sujeitos de suas experiências na pesquisa e na extensão condizem com as compreensões de Severino (2007) como um espaço de formação pedagógica; de Oliveira e Garcia (2009), como um espaço privilegiado que caminha ao lado do ensino e da pesquisa com o fim de revelar e construir novos conhecimentos; e de Freire (1980), como construção do conhecimento nas relações homem-mundo, nas relações e ações de transformação sobre a realidade.

O tópico convergências teve como foco perceber no relato dos acadêmicos como eles percebem a sua formação inicial na práxis do ensino que articula as ciências existentes; da pesquisa que constrói o novo, confirma e contesta conhecimentos existentes; e da extensão que articula os interesses do ensino e da pesquisa (Frantz y Silva, 2002).

Ao considerar que a formação precisa de apropriação do saber e a construção do saber na articulação destes três eixos, com o questionamento "Em que esta participação contribuiu na sua formação inicial durante o ensino de graduação?", os relatos manifestaram alguns indicadores significativos de qualidade para a formação, como: [a] um diferencial na formação; [b] auxílio para conciliar teoria e prática no cotidiano; [c] importância para a qualidade da aprendizagem; [d] construção do conhecimento fundamentado em teorias basilares; [e] importante para a carreira docente, a vida e as relações com o outro; [f] construir conhecimento sobre a formação do pedagogo.

Os futuros pedagogos em nenhum momento apresentam descontentamento da escolha, mesmo presente nos relatos anteriores algumas dificuldades durante a caminhada. As contribuições para a sua formação inicial enquanto inseridos em grupos de pesquisa para a articulação entre o ensino, a pesquisa e extensão foram expressivas, as amostragens das narrativas 
evidenciam o muito que o acadêmico pode ter de experiências para construção de novos conhecimentos na relação teoria e prática ao longo da trajetória universitária.

\section{Considerações finais}

Objetivado com o trabalho investigar como coadjuva a teoria e a prática na confluência do ensino, da pesquisa e da extensão na formação inicial do acadêmico do Curso de Pedagogia da Universidade Federal de Santa Maria, os elementos presentes a partir das experiências pela escolha desta experiência em projetos de pesquisa e extensão, os acadêmicos manifestaram preocupação com a sua formação, entendendo esta prática como construção de novos conhecimentos inter-relacionados aos estudos do ensino e um caminho para a continuidade da trajetória universitária em programas de pós-graduação.

Os desafios apresentados com relação aos anseios, dificuldades e problemas enfrentados pelos sujeitos da pesquisa a análise do que foi apresentado interpreta que breves diálogos entre o coordenador do grupo de pesquisa e seus integrantes são capazes de solucionar tais inquietações.

As convergências relatadas demonstram que a formação no ensino superior no entrelaçamento dos três pilares contribui para uma formação inicial, para que o futuro professor possa levar estas experiências para a sua sala de aula para instigar e incentivar o educando para uma relação de ensino e aprendizagem com qualidade.

\section{Referências bibliográficas}

Ministério da Educação de Brasil (1996). Lei de Diretrizes e Bases da Educação Nacional (LDB). n 9394/96.

Ministério da Educação e Cultura de Brasil (2006). Conselho Nacional de Educação. Resolução CNE/CP № 1, De 15 de maio de 2006. Institui Diretrizes Curriculares Nacionais para o Curso de Graduação em Pedagogia. 2006. Disponível em:http://portal.mec.gov.br/cne/arquivos/pdf/rcp01_06.pdf (01/09/2014). Ministério da Educação Brasil (2014). Conselho Nacional de Desenvolvimento Científico e Tecnológico - CNPQ. Bolsas e Auxílios. Disponível em:http://www. cnpq.br/pt/web/guest/bolsas-e-auxilios;jsessionid=81444BC17268C7FA00C20C84B3FD1EEE (01/09/2014)

Frantz, W. y Silva, E.W. (2002). A extensão universitária. In Silva, Enio Waldir da, As funções sociais da universidade: o papel da extensão e a questão das comunitárias. Ijuí, RS: UNIJUí,

Freire, P. (1980). Extensão ou Comunicação? $5^{\circ}$ ed. Rio de Janeiro: Paz e Terra. Freire, P. (2008). Pedagogia da autonomia: saberes necessários à prática educativa. $37^{\circ}$ ed. São Paulo: Paz e Terra.

Godoy A. S. (1995). Introdução à pesquisa qualitativa e suas possibilidades. Revista de Administração de Empresas,35(2), 57- 63, abril.São Paulo.
O estudo conseguiu importantes indicadores acerca de como vem se delineando o ensino, a pesquisa e a extensão na formação inicial dos futuros pedagogos e de seu significado para a qualidade dessa formação: [a] diferencial na formação; [b] auxílio para conciliar teoria e prática no cotidiano; [d] importância para a qualidade da aprendizagem; [e] construção do conhecimento fundamentado em teorias basilares; [ $f$ importante para a carreira docente, a vida e as relações com o outro; [g] construir conhecimento sobre a formação do pedagogo.

Vivenciar o ensino, pesquisa e extensão e analisar as contribuições dos sujeitos da pesquisa com os mesmos movimentos de formação inicial, trazem para a reflexão a importância da instituição de ensino superior organizar uma proposta de formação do pedagogo que valorize a indissociabilidade entre os três pilares; que incentive e atenda os diferentes perfis dos acadêmicos pertencentes ao curso do período diurno e/ou noturno. Para que todos tenham a possibilidade desta experiência é necessário que os grupos de pesquisa participem mais ativamente do ensino de graduação com suas propostas de estudos e pesquisas para os acadêmicos compreenderem o valor e significado deste saber na construção dos conhecimentos. Quanto aos professores, cabe-lhes o discernimento de elaborar um planejamento em conjunto com todos que integram o seu grupo de estudos, incluindo atividades avaliativas colaborativas, com o objetivo de estimular a troca de ideias para solucionar situações problemas, assegurando um ensino e aprendizagem individual e coletivo de qualidade, sem sobrecarregar os estudantes durante o ensino de graduação.

Moraes, R. (2007). Análise Textual Discursiva. Roque Moraes, Maria do Carmo

Galiazzi. Ijuí: Unijuí,

Oliveira, T. M. N. de y Garcia, B. R. Z. (2009). A extensão e o seu papel na formação acadêmica. Revista Univali. Itajaí,14(1), 111-117. Editora da Univali. Pimenta, S. G. (1994). O estágio na formação de professores unidade teoria-prática. São Paulo: Cortez.

Severino, A. J. (2007). Metodologia do trabalho científico. São Paulo: Cortez. Universidade Federal de Santa Maria (2012). Projeto Político Pedagógico do Centro de Educação, 2012. Disponível em:http://w3.ufsm.br/ce/ (01/09/2014). Universidade Federal de Santa Maria (2008). Política de Extensão da Universidade Federal de Santa Maria.Julho, 2008. Disponível em:http://w3.ufsm.br/pre/images/ anexos-do-site/Politica.pdf(10/10/2014).

Universidade Federal de Santa Maria (2012). Projeto Político Pedagógico do Curso de Pedagogia Licenciatura Plena Noturno. Estratégias Pedagógica. Disponível em:http://w3.ufsm.br/prograd/index.php/documentos/ppcs-projetos-pedegogicos/8-paginas/10-cursos-de-graduacao (10/10/2014).

Universidade Federal de Santa Maria [U4] Pró-Reitoria de Pós-Graduação e Pesquisa. Grupos de Pesquisa - Ciências Humanas. Disponível em:http://prpgp.ufsm. br/pesquisa/grupos-de-pesquisa(10/10/2014). 